\title{
Epidemiology of Snakebites Based on Field Survey in Chitwan and Nawalparasi Districts, Nepal
}

\author{
Pandey, Deb Prasada,b
}

aBirendra Multiple Campus, Tribhuvan University, Bharatpur, Chitwan, Nepal

bAssociation for Nature Conservation and Social Upliftment, Nepal

\begin{abstract}
Introduction: Snake envenomation is a major public health issue in the rural tropics, but there is no accurate figure of incidence of snakebite. Few studies have looked at the epidemiology of venomous snakebite in Nepal.

Methods: Using data collection sheets, enumerators randomly sampled, visited, and interrogated 20\% of the population from each district.

Results: Of the 2,186 snakebite cases studied in two districts from April to September 2005, 66\% were from Nawalparasi and $34 \%$ from Chitwan. 54\% were males. 56\% of patients consulted traditional healers. Most bites occurred in those 10-20 years of age and in those engaged in outdoor and agricultural (farmers) activities, but I should note that 15\% occurred during sleep. Extremity bites accounted for $94 \%$, with $66 \%$ in the lower extremities and $28 \%$ in the upper extremities. Of the total cases, $58 \%$ were nonenvenomations and $42 \%$ were envenomations. Of the total venomous cases, $27 \%$ died; which is $12 \%$ of the total snakebites (2,186). The majority of bites occurred in the summer.
\end{abstract}

Conclusions: This epidemiological study vividly depicted the health hazards of snakebites in two areas of rural Nepal.

\section{INTRODUCTION}

There are no accurate figures for the incidence of snakebites and associated morbidity and mortality, though some estimateslargely from reviews of hospital records-have been made. Two regions known for snakebite problems are South East Asia and Africa. In Africa the annual incidence of snakebites is 50-100 bites per 100,000 in dry savannah and Sahara [1]. In developing countries, snakebites are a significant occupational injury, particularly affecting agricultural workers, fishermen, and hunters [2].
In the Kingdom of Nepal, more than 1,000 people suffer from snakebites while more than 100 (10\%) people die of snakebites every year [3]. In 2001, a national Nepali newspaper reported snakebite statistics from 2000: 76 (15\%) deaths occurred among 523 people who suffered snakebites [4]. A community-based study in Southeastern Nepal estimated 162 deaths per population of 100,000 [1].

In 2003 Bista et al. mentioned that $72.7 \%$ (435) of the total 598 reported venomous snakebite cases in Nepal were greater than 15 years of age. Among 456 cases, $46.7 \%$ were bitten on legs and feet, $43.8 \%$ were bitten on hands and fingers, $8.2 \%$ were

Keywords: snakebites, epidemiology, venomous, non-venomous, mortality, morbidity

Notes: Funding provided by the University Grant Commission, New Baneshwor.

Acknowledgements: My special thanks go to Prem Neupane, Lekh Nath Acharya, Saraswoti Pandey, Bhawani Shankar Sigdel, Lok Raj Kafle, Govinda Neupane, Gita Neupane, Ram Nares Prasad Gupta and Mani Kantha Kandel from Nawalparasi and to Nava Prasad Pandey, Ishwori Prasad Pandey, Meena Kafle, Sita Poudel, Ramananda Subedi, Narayan Dhakal, Jeevan Chaudhary, and Sunita Chaudhary from Chitwan for their immense support in collecting data from allotted sampling units. I would also like to thank the University Grant Commission, Sanothimi, Bhaktapur, for the research grant to accomplish this research project.

Corresponding Author: Pandey, Deb Prasad, Dept. of Zoology, Birendra Multiple Campus, Tribhuvan University Bharatpur, Chitwan. Email: debpandey@gmail.com 
bitten in the head and neck region, and $1.3 \%$ were bitten on other parts of the body. In Nepal, males accounted for $51.3 \%$ of total snakebite cases [5]. In 2000 Devkota et al. observed that the incidence of snakebites was slightly higher among Nepalan males (54\%) than females, and most victims were bitten at night between 7 to $12 \mathrm{pm}$ [6]. In 2001 Devkota et al. also mentioned that incidence of snakebites was slightly higher among males (53\%) than in females and was more frequent in the 15 to 45 years age group (67\%). They observed that snakebite victims were mostly bitten during the day (61\%) [7]. In 2004 Sharma et al. indicated that $75 \%$ of snakebite patients from a clinico-epidemiological study in eastern Nepal were between 11 to 40 years [8].

The purpose of this study was to characterize the epidemiology of snakebites in the Chitwan and Nawalparasi districts of low land Nepal. This study was needed because most trained Nepalan health workers who report on such injuries are urban based where snakebites are rare. Most rural snakebite victims do not seek formal hospitalization but seek treatment from traditional healers. Existing epidemiological data in Nepal may be deficient in that it relies exclusively on hospital register analysis, which underestimates the true impact of snakebite in the community. Our study would have great significance regarding the management and epidemic of snakebites in a rural area.

\section{METHODOLOGY}

The study was inclusively conducted from April to September 2005. Demographic data were obtained from a 2001 Population Census, Central Bureau of Statistics (CBS), Kathmandu, Nepal. Tippett's table of random numbers was used to sample each districts 20\% sampling units [such as Village Development Committee (VDC) and Municipality]. Of the 38 potential sampling populations (36 VDCs and 2 municipalities) in the Chitwan district, 8 VDCs were selected. The VDCs covered $21 \%$ of the total sampling population and $20 \%(96,474)$ of the total human population in Chitwan. Of the 74 sampling populations (73 VDCs and 1 municipality) in the Nawalparasi districts, 15 communities (14 VDCs and 1 Municipality) were selected. The 15 communities in Nawalparasi covered $20 \%$ of total sampling population and $27 \%$ $(153,261)$ of the total human population. According to the 2001 Nepalan census, the total population of Chitwan and Nawalparasi was 472,048 and 562,870 respectively. Well-trained enumerators performed door-to-door visits in each of the allocated sampling units. They used a questionnaire study of retrospective snakebites in the selected population. Using a pre-established questionnaire form, they queried 2,186 respondents who suffered a snakebite within their lifetime, and they also queried victims' relatives or neighbors who remembered additional snakebite cases in their vicinity. Since some snakebite victims may have been absent (due to migration or death) during the study period, the data was recorded from the secondary person's (victims' relatives or neighbors) recollection of the incident. During field visits, houses with no snakebite events were downshifted. In this way data from 1946 to 2005 were amassed. Data collection activities were reviewed and cross-checked regularly to minimize data collection error.
This study defined venomous and non-venomous cases on the basis of victims' replies to symptoms after bites and by secondary respondents for victims who suffered death. To determine the prevalence of snakebites, we used the total number of snakebite cases that occurred in 2004 from both districts and divided it by the total population of sampling units studied. The quotient was then multiplied by 100,000 . Similarly, the number of deaths per 100,000 was determined. To verify data, each data sheet included a column for the signature of the respondents and enumerators. The data extracted by multiple persons were computer crosschecked to eliminate potential duplications, and all data were edited, coded, and classified to meet objectives. Tabulation of data was done for summarizing, enumerating, and statistical display of data. Finally, data were analyzed and characterized by percentage.

\section{RESULTS}

2,186 snakebite cases were recorded in two districts of the Southern part of Western and Central Nepal from 1946 to 2005. Of the total, 748 (34\%) were reported from Chitwan and 1438 (66\%) from Nawalparasi. 921 (42\%) were venomous cases, of which $27 \%$ (253) died (12\% of the overall total). $63 \%$ of these cases were recorded from Nawalparasi, and $37 \%$ of these cases were recorded from Chitwan. For the last year sampled, 2004, there were 274 snakebites of which 31 resulted in deaths. The data is equivalent to 110 snakebites and 12 deaths per 100,000 people per year.

1,180 of snakebite cases $(54 \%)$ were male. The greatest number of snakebites (27\%) occurred in those 10-20 years of age; the greatest number of deaths occurred in those 30 to $40 \mathrm{yrs}$ of age. Most snakebite victims (41\%) were brought to a hospital emergency department within one to two hours after a bite. This is when the most absolute number of deaths occurred; however, the proportions of snakebite cases and death were higher when time to hospital arrival exceeded 6 hours (Table 1, 2).

Snakebites occurred at different times:

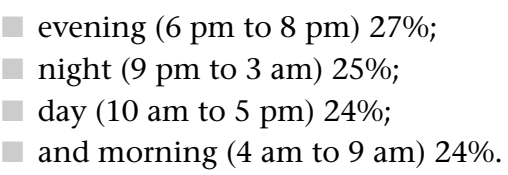

$57 \%$ of the total respondents illogically claimed their ability to identify the species of snake, and so I could not enumerate species of snakes. The other $43 \%$ were unable to determine the species of snake because of lack of knowledge, poor visibility in darkness, or poor visibility in tall vegetation. $56 \%$ consulted or depended upon traditional healers; $12 \%$ used some first-aid measure before arrival at hospital, and the rest directly presented to a hospital for treatment. The majority of deaths could be due to dependency on traditional healers who used traditional treatments such as tight tourniquets, local incision, suction, snake stone (Garud Dhunga), herbal matters, and vacuum extraction with application of the anus of hens, thus delaying access to a proper treatment center. 


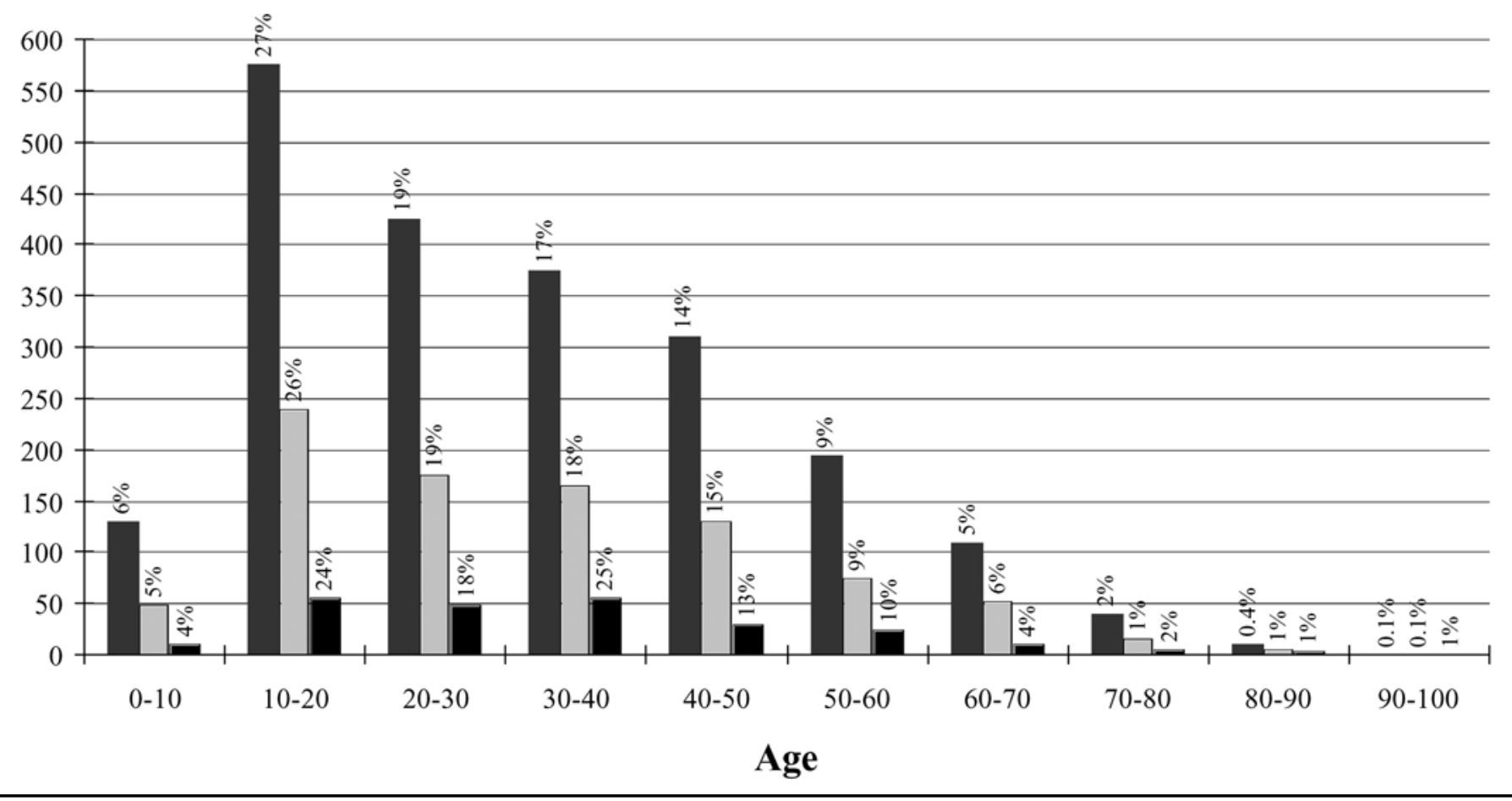

The main activity of victims at the time of a bite was fieldwork (32\%), followed by indoor activities (24\%), sleeping in a bed (15\%), walking on the road and ground (14\%), fishing and snail collection in crop-fields, river, stream, and other places (5\%), other activities (4\%), playing on the road, ground, or at school (3\%), and swimming and baths in a natural body of water (3\%). $61 \%$ of snakebites occurred during outdoor and agriculturerelated activities.

Farmers were the most severely affected occupational group (59\%); followed by students (27\%), housewives (6\%), and others such as teachers, army members, policemen, drivers, businessman, and others (8\%). Bites to the extremities accounted for 94\%: 66\% were in the lower extremities (legs) and 28\% were in the upper extremities. Main body parts accounted for $3 \%$ of snakebites, $2 \%$ in the head region, $1 \%$ in the neck region, and $0.2 \%$ in the area of genital organs. The seasonal distribution of snakebites was as follows; $65 \%$ occurred in the summer, $21 \%$ in the spring, $10 \%$ in the autumn, and $4 \%$ in the winter.

\section{DISCUSSION}

In this study, it was estimated that there were 110 snakebite cases and 12 deaths per 100,000 per year. The former was comparable to the epidemic of snakebites in Africa, the dry Savannah, and Sahara and the later was quite minimal compared to deaths reported in SE Nepal [1]. Of the total snakebite cases, the fatality rate in our study was $12 \%$, which was in between the findings mentioned in Annual Report of Ministry of Health, Nepal and in Rising Nepal [4]. The majority of deaths could be due to the delay in getting to a treatment center and the dependency on traditional healers for treatment. The age, sex, and incidence of snakebite cases shed light on vulnerable section of the population. The gender difference in this study was similar to the findings of Devekota et al., and Bista et al. $[6,7,5]$. The greater proportion of male victims suggests a special risk associated with outdoor activities. Snakebites were more frequent in victims 10 to 50 years of age, which was analogous to the Nepal findings of Devekota et al., Sharma et al., and Bista et al. $[7,8,5]$. The risk of snakebite increased with age, possibly due to the greater outdoor exposure of adults. On the other hand, the snakebite cases incrementally decreased in ages greater than 20 to 30 years of age, which corresponds to their lesser activity in later ages (Table 1).

Although the maximum number of deaths occurred within the first 1 to 2 hours of hospital arrival, the proportion of snakebite cases and deaths were higher when the time taken to arrive at a treatment center was greater; this was observed by Sharma et al. in 2004 [8]. Snakebite deaths are a result of factors other than age, possibly including the absorbed amount of venom per $\mathrm{kg}$ body weight, time to get to a hospital after a 
Table 2: Time to Hospital, Snakebites, and Deaths

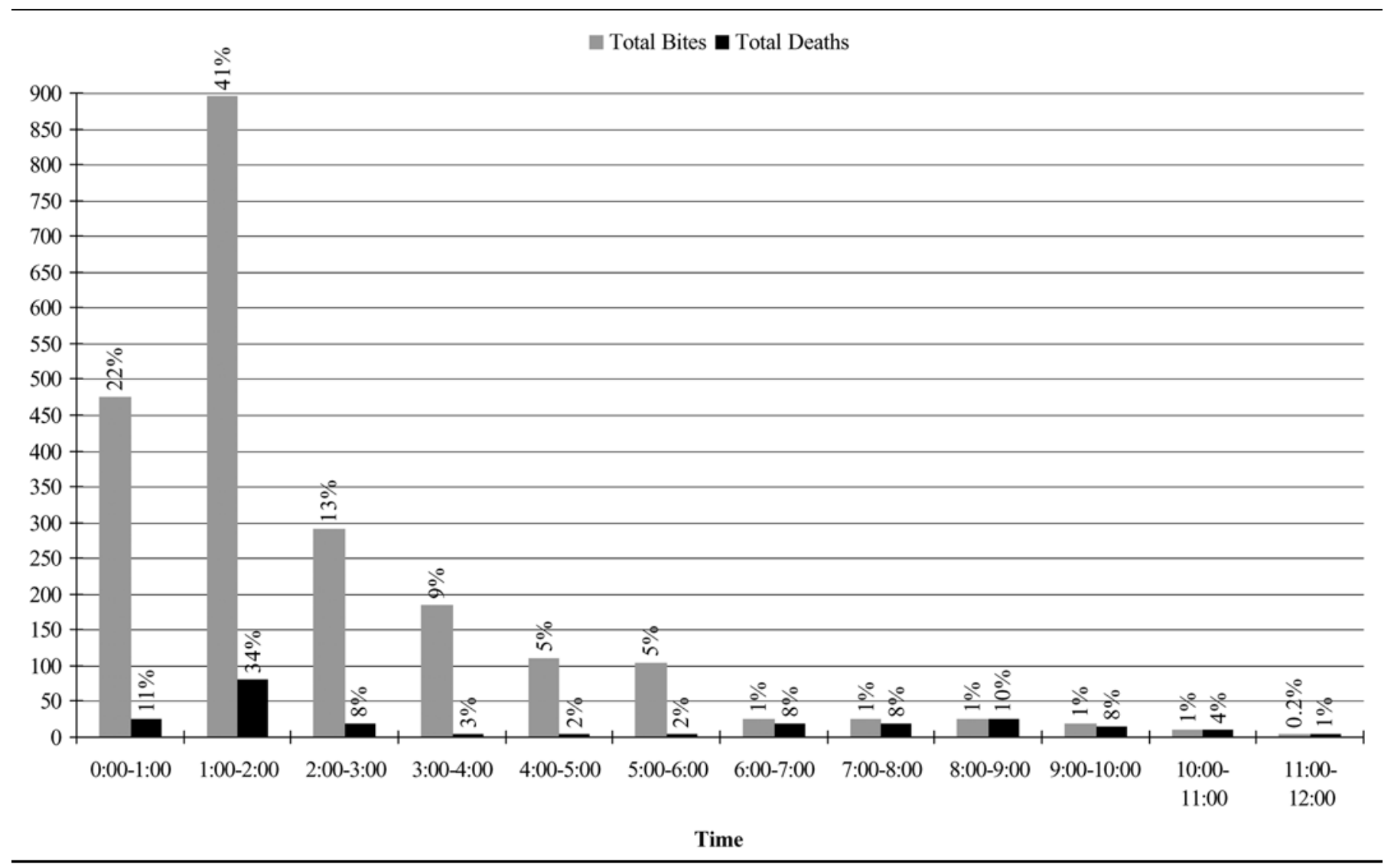

snakebite, and management after arrival [9]. The time of the snakebite observed in this study was supported by the findings of Devekota et al. in 2000 [6]. Unlike this result, Devekota et al. found most bites occurred during the day [7]. However, in this study, evening and nights were the most risky time for snakebites, which reflects the nocturnal habits of snakes and lack of visibility by people. Species of snakes could not be enumerated because respondents lack knowledge of different types of species. However, based on respondents' replies, Kraits, Cobras, and Vipers are common venomous snakes in that area.

$56 \%$ of snakebite victims consulted the traditional treatment system. But Snow reported that up to $80 \%$ of snakebite victims first consult traditional practitioners before visiting a medical center [10]. Hence, the majority of deaths could be due to dependency on traditional healers and a delay in access to proper treatment centers. Of the total snakebite victims, $61 \%$ were bitten during outdoor and agriculture related activities; comparable to the $65 \%$ recorded by Sharma et al. [8]. Those performing outdoor and agricultural activities have a greater risk of snakebite, particularly farmers who have the greatest risk. Devkota et al., Shah et al., and Sharma et al. documented analogous findings $[7,2,8]$. The location of a bite may vary. This study found that $94 \%$ of bites involved an extremity (66\% lower and $28 \%$ upper). The greater percentage of bites to the lower extremity suggests an unintentional etiology in the majority of cases. Studies by Warrel, Devkota et al., Sharma et al., and Bista et al. support these findings $[11,7,8,5]$. The peak incidence of summer snakebites is partly due to the abundant rainfall and food during summer months and the minimal rainfall, food, and hibernation of snakes in the winter months. This is akin to the findings of Hansdak et al. [12].

\section{LIMITATION OF THE STUDY}

Because of death, migrations, and the difficulty associated with the memory of respondents, a retrospective data of snakebite cases could not be completely verified. Respondents estimated time of arrival to the hospital. Enumerators could not assess dry bites because respondents were unable to address the nature of the laceration. This may be due to dependency on traditional healers or lack of knowledge.

\section{CONCLUSION}

The epidemiological assessment of snakebites in the Chitwan and Nawalparasi districts of Lowland Nepal indicated an epidemic health hazard. Public awareness programs about snakes, immediate snakebite management, and immediate access to a snakebite treatment centre could be instituted in these areas to diminish 
the dependency on the traditional healer and to standardize the health of this rural population.

The authors have no potential financial conflicts of interest to report.

\section{REFERENCES}

1. WHO 2005. Blood Products and related Biologicals: Animal sera-Available from http://www.who.int/bloodproducts/ animal_sera/en

2. Shah KB, Shrestha JM, Thapa CL. Snakebite Management Guideline. HMG, Nepal, Ministry of Health, Department of Health Services, Epidemiology and Disease Control Division, Zoonoses Control Sub-section. 2003;3.

3. Ministry of Health, Epidemiology and Disease Control Division. HMG, Nepal. Incidence of Poisonous Snakebite in Nepal. Annual Report. 2001;63-71.

4. Snake Bite: Over 100 die yearly in Nepal. The Rising Nepal, Katmandu. Feb. 01, 2001. Available from http:// www.nepalnews.com.np/contents/englishdaily/trn/2001/feb/ feb01/local.htm

5. Bista MB, Banerjee MK, Thakur GD, Shrestha JM., Upadhyay PK, Bhandari R. Annual Report 2002 and 2003.
Epidemiology and Disease Control Division. HMG, Ministry of Health, 2005;58-64.

6. Devkota UN, Steinmann JP, Shah LN. Snakebite in Nepal; A study from Siraha District, Nepal. J. Nep. Med. Ass. 2000; 39(134):203-209.

7. Devkota U N, Steinmann JP, Kathayat JB. Epidemiology of Snakebite; A study from Choharwa Army Camp, Siraha, Nepal. J. Nep. Med. Ass. 2001;40(138):57-62.

8. Sharma SK, Chappuis F, Jha N, Bovier PA, Loutan L, Koirala S. Impact of Snake Bites and Determinants of Fatal Outcomes in Southeastern Nepal. Am. J. Trop. Med. Hyg.

2004;71(2):234-238.

9. Russell FE. Snake-venom Poisoning. Philadelphia, JB Lippincott Company. 1980;235-285.

10. Snow RW. The Prevalence and Morbidity of Snakebite and Treatment-seeking Behaviour among a Rural Kenyan Population. Ann. Trop. Med. Parasitol. 1994;88:665-671.

11. Warrel DA. Venoms, Toxins and Poisons of animals and plants. 3rd ed. Vol. 1. In: Oxford Textbook of Medicine; Wealtherall DJ, Ledingham JGG, Warrell DA eds; Oxford University Press, Oxford. 1996.

12. Hansdak SG, Lallar KS, Pokharel P, Shyangwa P, Karki P, Koirala SA. Clinico- epidemiological study of snakebite in Nepal. Tropical Doctor 1998;28:223-226. 